\title{
Study of syndromic management of sexually transmitted infections in women of reproductive age at a tertiary care hospital in Tamil Nadu, India
}

\author{
Durga. K. ${ }^{1}$, Yuvarajan S. ${ }^{2}$, Yasodha S. ${ }^{3}$, Karthika K. ${ }^{4}$ \\ ${ }^{1}$ Dr. Durga K., Associate Professor, Department of Obstetrics and Gynaecology, SLIMS, Puducherry, ${ }^{2}$ Dr. Yuvarajan \\ Sivagnaname, Professor, Department of Pulmonary Medicine, SMVMCH, Puducherry, India, ${ }^{3}$ Dr. S. Yasodha, Associate \\ Professor, Department of Obstetrics and Gynaecology, SLIMS, Puducherry, ${ }^{4}$ Dr. K. Karthika, Assistant Professor, \\ Department of Obstetrics and Gynaecology, KGH, Tamil Nadu, India.
}

Corresponding Author: Dr. Durga. K, Associate Professor, Department of Obstetrics and Gynaecology, SLIMS, Puducherry, India. E-mail: drdurgakrish@gmail.com

\begin{abstract}
Background: Sexually transmitted infections (STI) rank among the top five conditions for which sexually active adults seek health care in the developing countries. The disease prevalence is about $6 \%$ in India. Syndromic management remains the core intervention in the WHO strategy in resource poor setting were laboratory services are not available. This study was done to determine the effectiveness of syndromic management of STIs in women of reproductive age [1549 years] attending gynaec outpatient block at Institute of Obstetrics and Gynaecology (IOG), Chennai. Methods: It is a prospective analytical study where 500 women of reproductive age symptomatic for STI were studied. A well-structured proforma was prepared for selection of women, history and examination. Based on the findings they were classified into STI syndromes and color-coded kits were given accordingly. Follow-up of patients was done to assess the effectiveness of treatment. Results: Overall there was $84.8 \%$ good response to Syndromic management. The follow up rate was $85.6 \%$. Vaginal discharge syndrome was the commonest syndrome followed by lower abdomen pain syndrome. Conclusion: STIs cause major health problem and it is important to diagnose and treat them at the earliest. Syndromic management is definitely an effective tool to manage STIs particularly in low resource settings.
\end{abstract}

Keywords: Sexually transmitted infections, Syndromic management, Bacterial vaginosis

\section{Introduction}

Sexually transmitted infections (STI) are prevalent worldwide. Presence of a STI/RTI (Reproductive tract infections) in the sexual partner increases the risk of acquisition of HIV from an infected partner by 8-10fold. Effective control of STI/RTI is a strong and most cost-effective strategy for reducing the transmission of HIV. In 1991, Syndromic management approach was

\section{The Need for Syndromic Management}

Due to non-availability of skilled and experienced persons at health centres to identify the infections and because of the expensive nature of sophisticated equipment's, which is not available everywhere, it is likely to miss infections. Missed infections are left untreated. Because of the time-consuming nature of the diagnostics tests there is a delay in starting treatment. In addition, there is only 50\% chance of diagnosing infections. Lack of diagnosing the STI and initiating treatment for STI at the prompt time will lead to continuous transmission of infections. Complications will follow and the sequele of STI will remain forever. All these factors lead to the evolution of Syndromic management.

Manuscript received: $10^{\text {th }}$ December 2019

Reviewed: $20^{\text {th }}$ December 2019

Author Corrected: $26^{\text {th }}$ December 2019

Accepted for Publication: $30^{\text {th }}$ December 2019

Obs Gyne Review: Journal of Obstetrics and Gynecology

Available online at: www.medresearch.in $231 \mid \mathrm{P}$ a g e 
Syndromic management remains the core intervention in the WHO strategy for delivering prevention and care for people with STI in resource poor setting were laboratory testing is not available [1,2]. It involves the use of simple flowcharts to help health care workers to identify groups of symptoms and easily recognizable signs and guide treatment that covers the most probable cause of the syndrome.

\section{The Common STI Syndromes}

1. Urethral discharge in male and cervicitis in female

2. Vaginal discharge in female

3. Genital ulcer in both

4. Genital ulcer- (allergic to penicillin) in both

5. Genital ulcer vesicles in both

6. Lower abdominal pain in female

7. Bubo (inguinal swelling) in both

Principles of syndromic management: It is first important to recognize the syndrome. The syndrome could be caused by one or more number of organisms and hence treatment with combination of drugs is essential. The drugs should cover the most common organisms potentially responsible for the syndrome. Organisms must be sensitive to the drugs prescribed to the patient.

This study was done mainly to assess the effectiveness of syndromic management of STI's in resource poor settings.

Table 1: Different STI syndromes and their colored kits for syndromic management.

\begin{tabular}{|c|l|c|l|}
\hline Kit. No & \multicolumn{1}{|c|}{ Syndrome } & Colour & \multicolumn{1}{|c|}{ Contents } \\
\hline 1 & $\begin{array}{l}\text { Urethral discharge, ano- rectal } \\
\text { discharge, cervicitis, asymptomatic } \\
\text { infection management }\end{array}$ & Grey & $\begin{array}{l}\text { Tab. Azithromycin 1g single dose } \\
\text { Tab. Cefixime 400mg single dose }\end{array}$ \\
\hline 2 & Vaginal discharge syndrome & Green & $\begin{array}{l}\text { Tab. Secnidazole 2g single dose } \\
\text { Tab. Fluconazole 150mg single dose }\end{array}$ \\
\hline 3 & Genital ulcer disease & $\begin{array}{l}\text { Tab. Azithromycin 1g single dose } \\
\text { Inj. Benzathine } \\
\text { Penicillin 2.4 MU(1)(sterile water 10ml) }\end{array}$ \\
\hline 4 & Genital ulcer disease & Blue & $\begin{array}{l}\text { Tab. doxycycline 100mg(30) } \\
\text { Tab. Azithromycin 1g }\end{array}$ \\
\hline 5 & Genital ulcer disease (herpes) & Yellow & $\begin{array}{l}\text { Tab. Acyclovir 400mg TID (7 days) } \\
\text { Tab. Metronidazole 400mg BID (14 Days) } \\
\text { Tab. Doxycycline 100mg BID (14 Days) }\end{array}$ \\
\hline 7 & Lower abdominal pain syndrome & Black & $\begin{array}{l}\text { Tab. Doxycycline100mg (21 Days) } \\
\text { Tab. Azithromycin 1g single dose }\end{array}$ \\
\hline
\end{tabular}

\section{Materials and Methods}

Study setting: The study was done at Institute of Obstetrics and Gynaecology (IOG), Chennai, Tamil Nadu, India.

Study design: The design employed in the present study was Hospital based prospective analytical study

Study participants: 500 women of reproductive age (15-49 years) attending gynecology outpatient department with symptoms suggestive of STI were included in the study.

Study duration: The duration of the study is 1 year (2010-2011) from the date of approval by Institutional IEC committee.

Sample size: Sample size of the study is calculated to be 500 using software Open Epi versions 3 based on the previous studies. 
Sampling method: 500 women of reproductive age (15-49 years) attending gynecology outpatient department with symptoms suggestive of STI were included in the study. The study group was selected according to inclusion and exclusion criteria. Those women who were willing for follow up were included in the study. Pregnant women and unmarried women with no sexual contacts were excluded from the study. Symptomatic male partners were referred to Venereology for examination and treatment. Follow up of women were done after 14 days of treatment during which abstinence was recommended. They were enquired about symptomatic relief, compliance and persistence of symptoms. Those who had persistent infections were investigated for the causative organisms and treated accordingly.

Data analysis: All collected data were entered in MS EXCEL sheet. Analysis would be done using the Multivariate logistic regression using SPSS version 15 [ Tools used Chi-square analysis].

\section{Results}

Table-2: Age distribution among symptomatic women.

\begin{tabular}{|c|c|c|}
\hline Age group (years) & Total no of women & Percentage of women \\
\hline $15-20$ & 30 & 6 \\
\hline $21-25$ & 94 & 18.8 \\
\hline $26-30$ & 242 & 48.4 \\
\hline $31-35$ & 78 & 15.6 \\
\hline $36-40$ & 30 & 6 \\
\hline $41-45$ & 25 & 5 \\
\hline $46-49$ & 1 & 0 \\
\hline
\end{tabular}

The prevalence of STI was high in the age group of 26-30 years (48.5\%) and low in the age group $>35$ years. The prevalence of STI in the age group of 21-25 years and 31-35 years were $18.8 \%$ and $15.6 \%$ respectively (Table 2 ).

Table-3: Percentage distribution of symptoms suggestive of STI among symptomatic women.

\begin{tabular}{|l|c|c|}
\hline Symptoms & No of cases & Percentage \\
\hline Vaginal discharge & 459 & 91.8 \\
\hline Itching & 167 & 33.4 \\
\hline Lower abdomen pain & 98 & 19.6 \\
\hline Dyspareunia & 109 & 21.8 \\
\hline Urinary complaints & 117 & 23.4 \\
\hline Menstrual irregularities & 30 & 6 \\
\hline Fever & 3 & 0.6 \\
\hline Ulcer & 2 & 0.4 \\
\hline
\end{tabular}

The most common presenting symptoms were vaginal discharge $(91.8 \%)$ and itching (33\%) followed by urinary complaints (23.4\%), Dyspareunia (21.8\%) respectively (Table 3$)$.

Table-4: Distribution of signs.

\begin{tabular}{|l|c|c|}
\hline Signs & No of Patients & Percentage \\
\hline Congestion & 229 & 45.8 \\
\hline Erosion & 158 & 31.6 \\
\hline Hypertrophy & 73 & 14.6 \\
\hline Vaginal discharge & 457 & 91.4 \\
\hline Intertrigo & 8 & 1.6 \\
\hline Cervical motion tenderness & 14 & 2.8 \\
\hline Fornix tenderness & 28 & 5.6 \\
\hline Excoriation & 4 & 0.8 \\
\hline Vesicles & 3 & 0.6 \\
\hline Ulcer & 9 & 1.8 \\
\hline Erythema & 11 & 2.2 \\
\hline
\end{tabular}


Cervical congestion and erosion were commonly noted signs among symptomatic women. However, the most common sign was vaginal discharge (Table 4).

Table-5: Distribution of STI syndromes.

\begin{tabular}{|c|c|c|}
\hline STI syndrome & No. of cases & Percentage of cases \\
\hline Vaginal discharge syndrome & 409 & 81.8 \\
\hline Lower abdomen Pain syndrome & 82 & 16.4 \\
\hline Cervicitis syndrome & 6 & 0.6 \\
\hline Genital ulcer (herpes) syndrome & 3 & 0 \\
\hline Genital ulcer syndrome & 0 & 0 \\
\hline Inguinal bubo syndrome & 0 & 1.2 \\
\hline
\end{tabular}

The most commonly diagnosed STI syndrome was vaginal discharge syndrome $(81.8 \%)$ followed by lower abdomen pain syndrome (16.4\%) (Table 5).

Table-6: Percentage distribution of STI syndrome showing improvement with syndromic management

\begin{tabular}{|c|c|c|c|c|}
\hline STI Syndrome & $\begin{array}{c}\text { Total no. of } \\
\text { cases }\end{array}$ & $\begin{array}{c}\text { Color of kit } \\
\text { And no. of kits given }\end{array}$ & $\begin{array}{c}\text { No. of cases } \\
\text { improved }\end{array}$ & $\begin{array}{c}\text { Percentage of } \\
\text { improved cases }\end{array}$ \\
\hline $\begin{array}{c}\text { Vaginal discharge } \\
\text { syndrome }\end{array}$ & 409 & $\begin{array}{c}\text { GREEN } \\
409\end{array}$ & 408 & 99.7 \\
\hline $\begin{array}{c}\text { Lower abdomen pain } \\
\text { syndrome }\end{array}$ & 82 & $\begin{array}{c}\text { YELLOW } \\
82\end{array}$ & 80 & 67.5 \\
\hline Cervicitis & 6 & $\begin{array}{c}\text { GREY } \\
6\end{array}$ & 4 & 100 \\
\hline $\begin{array}{c}\text { Genital ulcer syndrome } \\
\text { (herpes) }\end{array}$ & 3 & RED & 3 & 6 \\
\hline
\end{tabular}

Genital ulcer syndrome had $100 \%$ cure rate with syndromic management. Vaginal discharge syndrome had also $99.7 \%$ cure rate (Table 6).

The most common STI syndrome observed in this study was vaginal discharge syndrome ( $81.8 \%$ ) followed by lower abdomen pain syndrome (16.4\%) (Table 5). Most of the affected individuals were seen in 21-30 years of age group (87.4\%) (Table 2). 85.6\% (428) of patients came for follow up out off which $82 \%$ of patients (410) showed good response with syndromic treatment (Table 6). Good treatment response rate of $99.7 \%$ and $97.5 \%$ was observed in vaginal discharge syndrome group and lower abdominal pain syndrome group respectively. About $100 \%$ cure rate was observed in genital ulcer herpetic group. But in cervicitis group only $66.6 \%$ showed improvement (Table 6). On investigating further, they found to have concurrent candidial infection. Appropriate antifungal treatment was given to which they responded well. $14.4 \%$ cases did not return for follow up of which $2.8 \%$ were non complaint with drugs. About 5 women (1\%) had persistent infections. They were further investigated to identify the causative organisms and treated accordingly. Drugs used in Syndromic management approach were well tolerated by most of the patients with no reported adverse side effects.

\section{Discussion}

Syndromic Management is simple in its approach where in a single visit the patient is identified with a particular STI Syndrome and a cost-effective treatment is started immediately without wasting time for investigations. Misdiagnosis and inappropriate treatment are reduced. Appropriate and early treatment helps in prevention of transmission of HIV. The Mwanza Study is a community based randomized study done in Tanzania to show the strengthened STI case management of symptomatic persons using syndromic approach and a substantial reduction in the incidence of HIV to $40 \%$ over 2 years [4]. However Syndromic management is not free from limitations. Many STIs are asymptomatic and it is difficult to diagnose them. They are left untreated. Most of the affected individuals act as carriers and transmit infections to their partners. Since the treatment is on a single visit, after achieving symptomatic cure, patients do not regularly come for 


\section{Original Research Article}

follow up visits. Irregular compliance by the patient may lead to chances of development of resistant strain and recurrence. Over diagnosing of STI syndrome may lead to unnecessary wastage of drugs. Certain symptoms like leucorrhoea may be physiological or pathological. It is essential to differentiate them before starting treatment. The cost of drugs along with overdosing and side effects must be borne in mind before initiating treatment.

The most common STI syndrome observed in the present study was vaginal discharge syndrome $(81.8 \%)$ followed by lower abdomen pain syndrome (16.4\%). R George et al. also observed vaginal discharge as the most common STI syndrome in their study as well [5]. In the present study, highest number of patients of $87.4 \%$ were reported in the age group of 21-30 years which is the most active phase of sexual life. S.D. Chaudhary et al. also reported maximum number of patients in this same age group in their study [6].

The prevalence of STI was more commonly seen in homemakers although agricultural laborers were also at increased risk. Most of the affected homemakers were those whose husband were working out of station or they were lorry drivers. Education played a vital role among women which created awareness of safe sexual practices. Prevalence of STI was found to be higher among the less educated women. Cervical congestion and erosion were commonly noted signs among symptomatic women. However, the most common sign was vaginal discharge.

Overall 428 out of 500 patients which estimates to $85.6 \%$ came for follow up, of which 410 patients (82\%) showed good response with syndromic treatment. Good response was observed in vaginal discharge group, where 408 out of 409 patients improved with the treatment $(99.7 \%)$. Similarly, lower abdominal pain syndrome showed $97.5 \%$ improvement with the Syndromic management treatment. But in cervicitis group only $66.6 \%$ showed improvement due to concomitant candidial infection. Appropriate antifungal treatment was given to which they responded well. In a study in South Africa, the syndromic management protocols provided adequate treatment for more than $90 \%$ of patients with genital ulcer syndrome (GUS) [7]. The present study also reported $100 \%$ cure rate for genital ulcer of herpetic origin. In another study in Indonesia, the positive predictive value (PPV) of a syndromic approach for gonococcal and/or chlamydial urethritis was between $75 \%$ and $97 \%$, resulting in a low cost per real case treated [8]. In addition, the cure rate for urethral discharge with the syndromic approach was 99\% [8]. However vaginal discharge syndrome and cervicitis in females were found to be overtreated. The present study also reported only $66.6 \%$ cure rate in cervicitis group.

About 72 out of 500 patients $14.4 \%$ did not return for follow up. 14 out of 500 patients 2.8\% were non complaint with drugs. About 5 women (1\%) had persistent infections. They were further investigated to identify the causative organisms and treated accordingly. Drugs used in Syndromic management approach were well tolerated.

Guidelines for the management of STI by WHO- 2003 [3] and the National Guidelines on Prevention, Management and control of RTI/ STI - 2007 [9] states that syndromic management remains the core intervention in the WHO strategy for delivering prevention and care for people with sexually transmitted infections in resource-poor settings where laboratory testing is not available. The syndromic approach, which can be used at all levels of health care treats mixed infections, and prospective studies provide some evidence of effectiveness in the management of symptomatic urethritis and epididymitis in men and genital ulcer disease in both women and men $[10,11,12]$.

Limitations of the study: The syndromic flowchart for the management of vaginal discharge does not work well for controlling sexually transmitted infections in women because this symptom is a poor proxy for endocervical chlamydia and gonorrhoea even in high prevalence areas [13]. Apart from increased drug costs, overtreatment of vaginal discharge exposes women to the side-effects of multiple drugs, changes in the vaginal flora that might then exacerbate the symptoms [14].

In spite of its limitations, the syndromic approach is at present the most realistic option for the management of STIs in resource-poor settings.

\section{Conclusion}

In conclusion, the syndromic approach has been a major step forward in rationalizing and improving management of STI and its impact on the STI epidemic has been observed in various settings. However, syndromic algorithms have some shortcomings, and they should be periodically revised and adapted to the epidemiological patterns of STI in a given setting. 
Original Research Article

\section{What the study adds to the existing knowledge?}

Traditionally, screening tools are used to minimize the number of more expensive standard diagnostic tests by identifying a group of people with infection in areas of higher prevalence. The development of simple, cheap and rapid diagnostic tests is considered by STI control programme managers and STI specialists which has become an absolute priority in STI research. These tests may represent an important breakthrough for STI control in symptomatic and asymptomatic women in developing countries.

\section{Authors contribution}

Dr. Durga: Formulated study design, data collection and preparation of the manuscript

Dr. Yuvarajan Sivagnaname: Statistical analysis.

Dr. Yashoda S.: Data collection/Final proof reading

Dr. Karthika K.: Reference checking.

Funding: No funding sources

Conflict of interest: None declared

Ethical Approval: This study was approved by the Institutional Ethics Committee

\section{References}

1. Low N, Broutet N, Adu-Sarkodie Y, Barton P, Hossain M, Hawkes S. Global control of sexually transmitted infections. The Lancet. 2006; 368 (9551): 2001-2016. doi: https://doi.org/10.1016/S0140-6736 (06) 69482-8.

2. WHO- Prevention and control of sexually transmitted infections: WHO. Prevention and control of sexually transmitted infections: draft global strategy. Available at http://www.who.int/reproductivehealth/docs/stis_strategy.pdf (accessed Sept 19, 2006).

3. WHO- Guidelines for the management of sexually transmitted infections; revised version2003. Geneva: WHO, 2003. Available at https://www.who.int/hiv/ pub/ sti/pub6/en/.

4. Gilson L, Mkanje R, Grosskurth H, Mosha F, Picard $\mathrm{J}$, Gavyole A, et al. Cost-effectiveness of improved treatment services for sexually transmitted diseases in preventing HIV-1 infection in Mwanza Region,
Tanzania. The Lancet. 1997; 350(9094):1805-1809. doi: https ://doi.org/10.1016/S0140-6736(97)08222-6.

5. George R, Thomas K, Thyagarajan SP, Jeyaseelan L, Peedicayil A, et al Genital syndromes and Syndromic management of vaginal discharge in a community setting. Int J STD AIDS. 2004; 15(6): 367-370. doi: https: //doi.org/10.1258/095646204774195191.

6. Chaudhary SD. Pattern of STDs in Rohtak. Indian J Sex Transm Dis. 1988;9:4-7.

7. Htun Y, Morse SA, Dangor Y, Fehler G, Radebe F, Trees DL, et al. Comparison of clinically directed, disease specific and syndromic protocols for the management of genital ulcer disease Lesotho Sex Transm Infect. 1998;74(1):S23-S28.

8. Djajakusumah T, Sudigdoadi S, Keersmaekers $\mathrm{K}$, Meheus A. Evalution of syndromic patient management algorithms for urethral discharge. Sex Transm Infect. 1998;74 (1):S29-S33.

9. National Guidelines on Prevention, Management and control of RTI/ STI - 2007. Available at http://naco. gov.in/sites/default/files/National_Guidelines_on_PMC _of_RTI_Including_STI\%201.pdf.

10. Dallabetta GA, Gerbase AC, Holmes KK. Problems, solutions, and challenges in syndromic management of sexually transmitted diseases. Sex Transm Infect. 1998; 74(1):S1-11.

11. Pettifor A, Walsh J, Wilkins V, Raghunathan P. How effective is syndromic management of STDs: A review of current studies. Sex Transm Dis. 2000;27 (7): 371-385.

12. Garcia PJ, Gotuzzo E, Hughes JP, Holmes KK. Syndromic management of STDs in pharmacies: evaluation and randomised intervention trial. Sex Transm Infect. 1998;74(1):S153-S158.

13. Trollope-Kumar K, Guyatt G. Syndromic approach for treatment of STIs: time for a change. Lancet 2006; 367 (9520): 1380-1381. doi: https:// doi. org/10. 1016/ S0140-6736 (06)68593-0.

14. Bolan G, Ehrhardt AA, Wasserheit JN. Chapter 8. Gender perspectives and STDs. In: Holmes KK, Sparling PF, Mårdh PA, et al, eds. Sexually transmitted diseases, $3^{\text {rd }}$ Ed, New York: McGraw-Hill, Inc, 1999: pp 117-127.

\section{How to cite this article?}

Durga. K, Yuvarajan S, Yasodha S, Karthika K. Study of syndromic management of sexually transmitted infections in women of reproductive age at a tertiary care hospital in Tamil Nadu, India. Obs Rev: J Obstet Gynecol 2019;5(5): 231-236.doi:10.17511/joog.2019.i05.04. 